\title{
O Mapa Geográfico de América Meridional, de Juan de la Cruz Cano y Olmedilla'
}

\begin{abstract}
André Ferrand de Almeida ${ }^{2}$
RESUMO: Este texto analisa a história da elaboração do Mapa Geográfico de América Meridional, de Juan de la Cruz Cano y Olmedilla, a gravação das diferentes edições do mapa, a sua circulação e recepção durante a segunda metade do século XVIII, à luz do conflito entre as coroas ibéricas acerca dos limites do Brasil.

PalAVRAS-ChaVE: Mapa. Cartografia impressa. América Meridional. Limites. Tratado de Santo Ildefonso.

ABSTRACT: This essay examines the history of the construction of the Mapa Geográfico de América Meridional (Map of South America) by Juan de la Cruz Cano y Olmedilla, how its various editions were engraved, as well as its circulation and reception during the second half of the $18^{\text {th }}$ century in the light of the ongoing dispute between Portugal and Spain over the boundaries of Brazil.

KEYWORDS: Map. Printed cartography. South America. Boundaries. Treaty of St. Ildefonso.
\end{abstract}

mapa da América Meridional desenhado por Juan de la Cruz Cano y Olmedilla (Figura 1) é, sem dúvida, para o conjunto da América do Sul, um dos mapas mais importantes que se imprimiram na Europa durante o século XVIII. Antes de discutirmos o seu longo e complexo processo de elaboração e os modos como foi lido e interpretado - e a utilização que terá tido -, passamos a descrever de forma sucinta o seu conteúdo.

título do mapa - Mapa Geográfico de América Meridional - foi colocado na oitava folha, numa cartela de grande riqueza iconográfica, com diferentes motivos alegóricos. Por cima da cartela, na sexta folha, temos uma coluna com o busto de Cristovão Colombo e uma legenda: A Castilla y a Léon Nuevo Mundo dio Colón. Por cima do busto, na terceira e na quarta folhas, estão colocados os escudos das principais cidades espanholas da América do Sul e,
1. Este texto retoma, com alterações, o que publicamos sobre este mapa em João Carlos Garcia (2001, p. 5361), e em Tesoros de la cartografia española (2001, p.181-182), de vários autores.

2. Centro de Estudos Geográficos da Universidade de Lisboa. Doutorando em História e Civilização no Instituto Universitário Europeu, em Florença. Mestre em História dos Descobrimentos e da Expansão Portuguesa pela Universidade Nova de Lisboa, tem-se dedicado à História do Brasil no período colonial, em particular à História da Cartografia. É colaborador regular da Área de Cartografia da Biblioteca Nacional de Lisboa desde 1998. E-mail: <andreferrand@gmail. com>. 


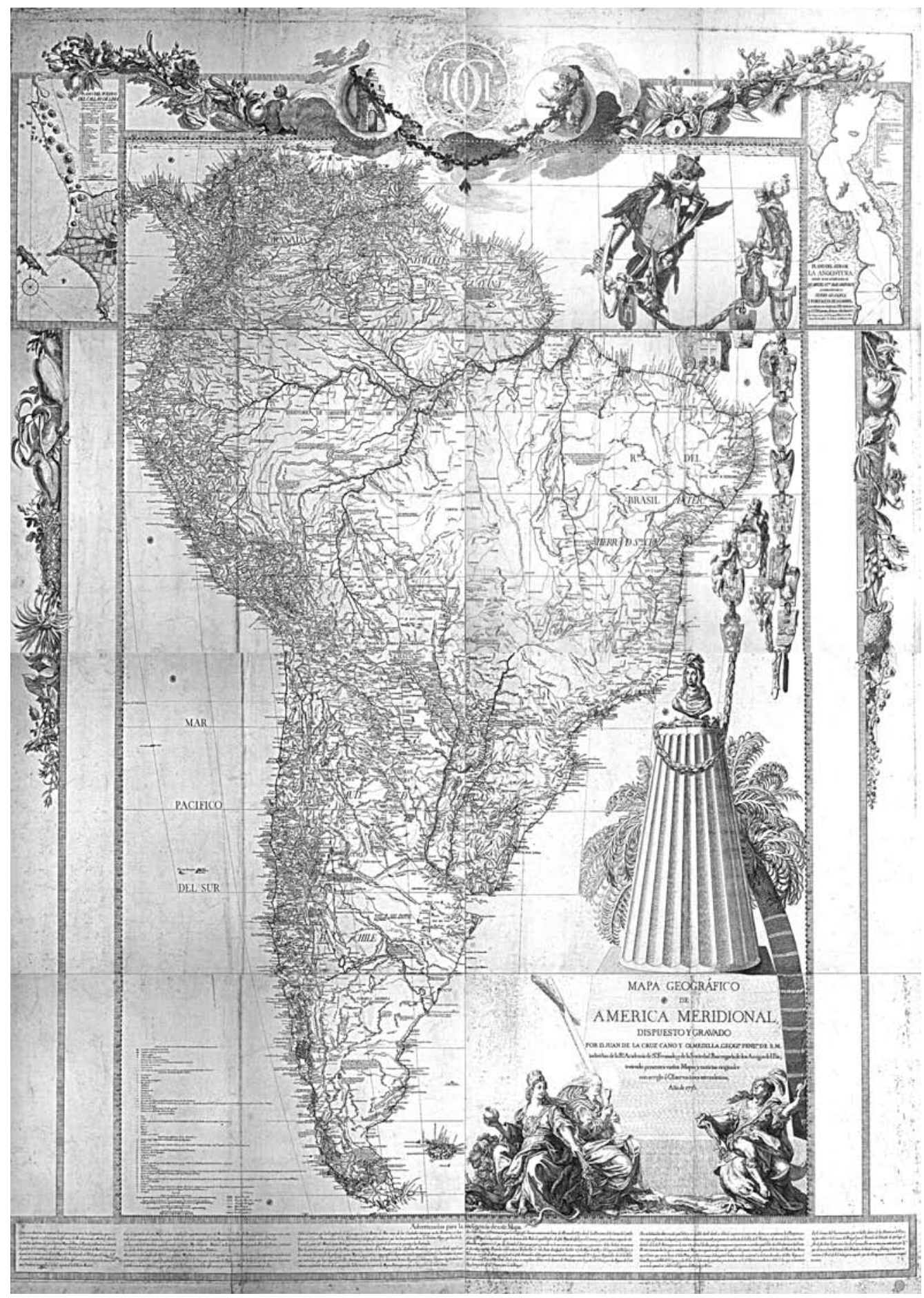

Figura 1 - Mapa Geográfico de América Meridional, dispuesto y gravado por D. Juan de la Cruz Cano y Olmedilla, Geog ${ }^{\text {to }}$. Pens ${ }^{\text {do }}$. de S. M. individuo de la R. Academia de S. Fernando, y de la Sociedad Bascongada de los Amigos del Pais; teniendo presentes varios Mapas y noticias originales con arreglo á Observaciones astronómicas, Año de 1775. Dimensão: 263 x $183 \mathrm{~cm}$. Fundação Biblioteca Nacional - Rio de Janeiro. 
representando o Brasil, um escudo com as armas de Portugal. No bordo superior do mapa, na primeira e na segunda folhas, surge o símbolo da ordem de Carlos III, rodeado pelos escudos de Castela e Leão, unidos pelo Tosão de Ouro. Desse motivo central, saem uns ramos de vegetação tropical, que deslizam por todas as folhas, com exceção das duas últimas. Na primeira e na segunda folhas, temos, também, dois mapas inseridos: o Plano del puerto del Callao de Lima, ciudad capital del Reyno del Perú; e o Plano del sitio de la Angostura, donde se ha establecido el quartel Gral de R. Orinoco, la población de la Nueva Guyana fortaleza de S. Gabriel [...]. No extremo inferior do mapa, há um texto intitulado Advertencias para la inteligencia de este Mapa. Aí se explicam os meridianos de referência utilizados no mapa e os cálculos seguidos para traçar as possíveis linhas de demarcação entre os domínios portugueses e espanhóis, de acordo com - Tratado de Tordesilhas, bem como uma explicação acerca da Colônia do Sacramento e seu território.

No mapa estão representados com muito detalhe - especialmente para um mapa de pequena escala como este -,os territórios do Novo Reino de Granada, da Nova Andaluzia ou Província da Guiana, do Vice-Reinado do Perú ou Nova Castela, da Audiência de Charcas, o Reino do Chile e o Vice-Reinado de Buenos Aires, para além do "territorio de Misiones o país de las Amazonas", situado ao longo da bacia do rio Amazonas. As colônias estrangeiras - a Cayena francesa, o Suriname holandês e o Brasil, separado da bacia Amazônica e com a legenda correspondente "Reyno de Brasil anteriormente Tierra de Santa Cruz" - também figuram no mapa. Escusado será dizer que é sobretudo nos territórios sob domínio espanhol que encontramos maior abundância de topônimos e de informação geográfica, principalmente nas zonas costeiras, embora nos territórios do interior, onde se situavam a maior parte das missões entregues a diferentes ordens religiosas, também encontremos uma grande riqueza de informação. Ao contrário, no caso do Brasil, se excetuarmos a bacia amazônica e a região platina, o mapa de Cruz Cano não reflete o estado da cartografia portuguesa da época, quer no que toca ao litoral, quer no que respeita o interior. É de notar, por exemplo, a pouca atenção recebida pela região de Minas Gerais, uma das mais populosas do Brasil durante o sécuo XVIII. É possível que tal disparidade se deva à maior abundância de fontes cartográficas espanholas colocadas à disposição de Cruz Cano. Por outro lado, as autoridades espanholas estavam interessadas sobretudo em seu próprio território e nas áreas limítrofes, ou seja, ao norte, na região amazônica; no sul, na região platina, incluindo o Rio Grande de São Pedro e eventualmente a ilha de Santa Catarina; na região central, onde os territórios das missões de Chiquitos e de Moxos confinavam com o Mato Grosso. Daí que o restante território do Brasil fosse objeto de menor atenção, uma vez que sobre ele não pesava qualquer disputa.

Sabemos que, entre 1775 e 1789, foram feitas quatro edições diferentes do $\mathrm{mapa}^{3}$. A primeira edição data de finais de 1775, provavelmente de outubro ou novembro, enquanto a segunda corresponde a fevereiro de 1776. A datação das edições terceira e quarta é menos precisa. A terceira edição terá
3. Para a datação das diferentes edições do mapa, seguimos o artigo de T. R. Smith (1966, p. 63-67) 
4. Idem, p.74.

5. Idem, p. 52

6. Ver R. Núñez de las Cuevas (1991, p. 190).

7. A este propósito, ver a carta de Grimaldi a Lopez de 30 de Agosto de 1766, citada em T. R. Smith (1966, p. 55).

8. Ver idem (p.56, nota 24) Segundo o autor, o mapa encontra-se na Sociedad Geografica de Madrid. sido impressa muito provavelmente no fim de 1776, seguramente depois do mês de julho, e certamente antes de 1785, ano em que Carmichael a enviou a Thomas Jefferson para ser reimpressa por Faden. Já a quarta edição, que apresenta modificações apenas na quinta folha, relativas ao estabelecimento do Vice-Reinado do Rio da Prata durante os anos 1776 e 1777, deve datar desse mesmo período, possivelmente já de 1777, e sabe-se também, com certeza, que é anterior a 1789, ano em que o mapa foi depositado na Real Calcografia. Foi, além disso impressa em papel que apresenta a marca de água FOO GVARRO, da casa Guarro, dos fabricantes de papel Francisco e Pedro Guarro, a quem Carlos III concedera, em 1773, devido à qualidade dos seus papeis, diversos privilégios. No século XIX, após 1861, foram impressos novos exemplares que, exceto no papel, são idênticos à quarta edição ${ }^{4}$. A reimpressão do mapa feita por Faden distingue-se facilmente das impressões realizadas em Espanha, não apenas por apresentar a data de 1799 e o nome do gravador inglês, mas também por não incluir todo o aparato iconográfico das diferentes edições dos mapas impressos em Espanha, além de ser feita em seis folhas, e não em oito, como o mapa original.

O mapa de Juan de la Cruz Cano y Olmedilla tem uma história longa e complexa. Em 1763, o marquês de Grimaldi, secretário de Estado de Carlos III, decidiu mandar gravar um novo mapa da América do Sul. Logo em dezembro do mesmo ano, Grimaldi deu ordens a Ventur de Llovera para comprar em Paris as chapas de cobre e o papel (do tipo que os franceses chamavam grand aigle) para se proceder à gravação e impressão do mapa. Da realização do mapa, foram incumbidos, em 1765, Tomás Lopez e Juan de la Cruz Cano y Olmedilla. Estes já tinham trabalhado juntos durante a sua permanência em Paris, tendo publicado, em 1755, um mapa do golfo do México e outro da América do Norte ${ }^{5}$. Agora, para corresponder à encomenda de Grimaldi, caberia a Tomás Lopez, na feitura do novo Mapa da América Meridional, a zona compreendida entre os $20^{\circ}$ e os $60^{\circ}$ de latitude, e a Cruz Cano toda a área a partir dos $60^{\circ} 6$. Não se sabe muito bem por que, mas Lopez acabou por desvincularse do projeto, ficando somente Cruz Cano responsável pela execução?.

Numa primeira fase, a idéia do marquês de Grimaldi era mandar gravar um mapa manuscrito da América Meridional, de grandes dimensões, da autoria de D. Francisco Millau y Maraval, um dos principais cartógrafos espanhóis que, na sequência do Tratado de Madrid de 1750, integrou as partidas do sul. Ignora-se o paradeiro deste mapa de Millau y Maraval, conhecendo-se apenas o seu Mapa de una parte de América Meridional, manuscrito, mas que data já de 1768. É, contudo um mapa de grandes dimensões $(333 \times 272 \mathrm{~cm})$, tal como aquele de que Cruz Cano se terá servido - e não é de se excluir que ele tivesse tido acesso a uma versão anterior deste mapa, datada, o mais tardar, de $1765^{8}$. Vale a pena recordar, a este propósito, a existência, na mapoteca do ltamaraty, de um outro mapa espanhol, manuscrito, da América Meridional, que, muito provavelmente, é da autoria de Millau y 
Maraval. Neste mapa, de cerca de 1761, já são incorporados alguns dos resultados das partidas de demarcação do sul?.

Seja como for, em 1767, Cruz Cano solicitou ao marquês de Grimaldi a autorização para fazer um novo mapa da América Meridional, em vez de limitar- se a copiar o mapa de D. Francisco Millau y Maravall. Este novo mapa seria feito numa projeção diferente, apesar de manterem-se idênticas as dimensões, devido ao tamanho das chapas de cobre já adquiridas, e teria por base mais de sessenta mapas e planos provenientes do Arquivo das Índias. Entre esses mapas - manuscritos e impressos - era certo haver não apenas mapas espanhóis, mas, também, franceses, ingleses, holandeses e, claro está, portugueses. Que ainda não foram suficientes, pois Cruz Cano solicitou a Grimaldi o seu apoio na obtenção de mais mapas. Nesta data, aparece pela primeira vez associado ao projeto o nome de Hipólito Ricarte. Enquanto Cruz Cano trabalharia apenas no desenho do mapa e na sua gravação, incluindo a parte decorativa, Hipólito Ricarte seria o responsável por gravar nele as letras ${ }^{10}$.

A partir de 1770, o processo de gravação foi progredindo, ainda que de forma bastante lenta, muito provavelmente devido à quantidade de trabalho necessária para realizar um mapa de pequena escala, como este, com as dimensões pretendidas $(263 \times 183 \mathrm{~cm})$. Só nos finais de 1775 foi impressa a primeira edição do mapa, a que se seguiriam outras, pouco depois. Antes de procurarmos perceber a razão dessa sucessão de edições do mapa num período de tempo tão curto la segunda edição é de fevereiro de 1776; e a terceira deve corresponder ao final do mesmo ano ou ao início do seguinte), é importante sublinhar que a oitava folha, onde está o título, apresenta - em todas as edições que se fizeram nos séculos XVIII, XIX e XX - a data de 1775, que, como vimos, só é válida para a primeira edição.

Em sua primeira versão impressa, o Mapa Geográfico de América Meridional tinha assinalada, de norte a sul, uma linha de fronteira que, de fato, correspondia a uma divisão entre o Brasil e os domínios espanhóis na América do Sul. Como chegou Cruz Cano a este traçado da linha de fronteira e em que se baseou para desenhá-la? A resposta não é simples, uma vez que nos faltam vários elementos para podermos fundamentar-nos com mais segurança. Thomas R. Smith, que estudou o mapa detalhadamente, considerou-com base nos mapas manuscritos reproduzidos na obra de Guillén y Tato - que as semelhanças entre a linha do mapa de Cruz Cano e a do Tratado de Madri eram apenas aparentes ${ }^{11}$. $\bigcirc$ que Smith parecia desconhecer era a existência do chamado Mapa das Cortes, que, ao contrário dos mapas reproduzidos por Guillén, foi o mapa oficial que esteve na base da assinatura do Tratado de Madri. Ora, comparando os dois mapas, é impossível não perceber que a linha traçada por Cruz Cano tem por base a do Mapa das Cortes, muito embora haja variações importantes, nomeadamente, na margem norte do Amazonas e na fronteira ocidental do mesmo rio, e no delinear da fronteira meridional do Brasil, compreendida entre o rio Paraguai e o Rio Grande de S. Pedro, que em Cruz Cano apresenta dois traçados alternativos $^{12}$. A existência de dois traçados para a fronteira meridional talvez
9. Cf. I. Adonias (1960, p. 433); e também A. Barreto (1976, p. 894-895).

10. Cf. T. R. Smith (1966, p. 53, 55-57).

11. Cf. J. F. Guillén y Tato (1942, láminas n.114, 115 e 118).

12. Ver o mapa da Figura 3 em T. R. Smith (1966, p.58). 
13. Cf. A. Sanz Tapia (1995, p. 1657).

14. Ver L. Ramos Gómez (1995).

15. Cf. D. Alden (1968, p.165-168).

16. Idem, p. 195-202; ver também D. Ramos Pérez (1974, p. 19). possa estar ligada a algum projeto de limites que remontaria a 1766 ou 1767 , quando ainda era possível, por parte da Espanha, aceitar esquecer a demarcação segundo o meridiano de Tordesilhas e negociar com Portugal com base nos territórios efetivamente ocupados na América do Sul' ${ }^{13}$.

O certo é que, em 1775, a figuração da linha de fronteira, quase reconhecendo de forma implícita uma demarcação que se encontrava abolida desde 1761, não deve ter sido do agrado de Grimaldi, que, com certeza, mandou apagá-la e ordenou nova edição do mapa. O mapa impresso que deveria ser utilizado pelos ministros e diplomatas espanhóis na preparação de uma solução para o diferendo com Portugal na América do Sul, não podia, como é evidente, apresentar quaisquer elementos que pudessem supôr um reconhecimento das usurpações territoriais do inimigo. Convém não esquecer que a estratégia espanhola já passava, então, por reclamar uma aplicação rigorosa do Tratado de Tordesilhas. Neste mesmo sentido, foi recuperada a Disertación Historica y Geografica de Jorge Juan e de António de Ulloa, impressa em 1749 mas nunca divulgada - e que o marquês de Grimaldi mandou traduzir e publicar (na França, em 1776), não sem antes ter mandado fazer algumas alterações no texło original, que o tornassem mais incisivo contra Portugal ${ }^{14}$.

O fracasso do ataque de uma grande armada espanhola a Argel, em julho de 1775, acabou por provocar uma reaproximação das duas cortes ibéricas. Mediante proposta de Grimaldi a Francisco de Sousa Coutinho, embaixador português em Madri, foram dados os primeiros passos para novas conversações de paz. Ao que parece, Grimaldi tinha obtido informações seguras sobre o reforço dos efetivos militares portugueses no Rio Grande do Sul e pretendia ganhar tempo. Aproveitou também para pedir ao conde de Aranda, embaixador espanhol em Paris, que solicitasse a Luís XVI que mediasse a disputa entre Portugal e Espanha. Por seu lado, o marquês de Pombal, percebendo que, depois da derrota de Alger, a Espanha estava negociando em posição de fraqueza, instruiu o embaixador em Madri para iniciar as conversações, enquanto enviava ordens ao marquês do Lavradio para reforçar a defesa da Colônia do Sacramento e conquistar as posições espanholas no Rio Grande de S. Pedro' ${ }^{15}$.

Mais uma vez, as iniciativas de paz tinham razões puramente conjunturais e, se ambas as partes manifestavam o aparente desejo de resolver o conflito pela via diplomática, o certo é que, paradoxalmente, os projetos bélicos coexistiam com elas. Só assim se explica que, muito antes de ter chegado a Madri a notícia da reconquista, em abril de 1776, da margem ocidental do Rio Grande de S. Pedro pelas tropas do tenente-general Böhm, também a Coroa espanhola já tivesse um plano para uma grande ofensiva naval e terrestre nos territórios em disputa. Os planos espanhóis remontavam pelo menos a outubro de 1775, e, em julho do ano seguinte, iá estava decidido o envio de uma expedição ao rio da Prata comandada por D. Pedro de Cevallos ${ }^{16}$.

As discussões diplomáticas continuavam, portanto. Ao longo do ano de 1776, o conde de Aranda foi ganhando um protagonismo cada vez maior na definição da estratégia a seguir, acabando muitas vezes por se sobrepor por 
completo ao marquês de Grimaldi. Esperava-se para breve que um congresso de paz se reunisse, em Paris, onde os representantes dos reis da França e da Inglaterra, enquanto mediadores, deviam encontrar-se com os embaixadores da Espanha e de Portugal para solucionar o conflito. Para preparar tais conversações, Grimaldi obteve o apoio de outros ministros para formar uma junta consultiva, presidida por José de Gálvez, ministro das Índias, e composta por alguns membros do Conselho das Índias com reconhecidas competências na questão sul-americana. Dela faziam parte, entre outros, D. Pedro de Cevallos, o marquês de Valdelirios e D. Francisco Arguedas. Estes dois últimos tinham sido comissários das partidas do sul no período posterior ao Tratado de $1750^{17}$.

Em junho de 1776, entre os principais documentos submetidos à Junta para análise e preparação das negociações com Portugal, contavam-se: a Memória (de 16 de janeiro de 1776), do embaixador português D. Francisco de Sousa Coutinho; a Disertación Historica y Geografica, de Jorge Juan e de António de Ulloa; e o Mapa de América Meridional, de Juan de la Cruz Cano y Olmedilla ${ }^{18}$. Sabemos, no entanto, que o mapa já se encontrava nas mãos de Grimaldi bastante antes, e que estava em poder do conde de Aranda pelo menos desde abril de 1776. Em 26 deste mês, Aranda refere a Grimaldi que, pelo mapa grande que the havia sido enviado, tinha-se apercebido da extensão da usurpação territorial portuguesa na América, insistindo que, por isso mesmo, devia reclamar-se o cumprimento estrito dos tratados ${ }^{19}$. Claro que era o Tratado de Tordesilhas que Aranda tinha em mente. Não que acreditasse ser possível chegar a um acordo com Portugal a este respeito, mas porque pensava ser necessário reclamar o máximo possível e mostrar grande determinação diante dos mediadores e de Portugal, de modo a obter um compromisso justo para a Espanha. Mais tarde, Aranda enviou nova carta a Grimaldi onde sugeria que se assinalassem, em dois exemplares do mapa de Cruz Cano, determinadas reivindicações territoriais, ficando um deles de posse da junta e devendo o outro ser enviado a ele, em Paris. Não se sabe quais foram as reivindicações territoriais pedidas por Aranda, mas o certo é que, por determinação de Grimaldi, a Junta reuniu-se para dar cumprimento à sua solicitação ${ }^{20}$.

Sabemos, portanto, que, para além dos exemplares que se encontravam nas mãos do marquês de Grimaldi e do conde de Aranda, houve mais cinco exemplares da segunda edição do mapa de Cruz Cano que foram entregues aos membros da Junta no início de junho de 1776. Dois anos mais tarde, nas instruções escritas para D. José Vertiz, seu sucessor no Vice-reino do Rio da Prata, D. Pedro de Cevallos refere explicitamente que the deixava um mapa da América do Sul, de Juan de la Cruz, para ajudá-lo nas demarcações de limites. Sinal que D. Pedro de Cevallos levara o mapa consigo em novembro de 1776, quando partiu com a armada de vinte mil homens à conquista da llha de Santa Catarina, da Colônia do Sacramento e do Rio Grande de S. Pedro. Se a distribuição do mapa esteve inicialmente restrita aos membros da Junta Consultiva, temos aqui um exemplo do alargamento desta difusão à América do Sul.

A questão da difusão do mapa de Cruz Cano é tanto mais importante
17. Idem, p.28; cf. também A. Sanz Tapia (1995, p 1670); e T. R. Smith (1966, p.69).

18. Sobre a Memória de D. Francisco de Sousa Coutinho e a resposta do Marquês de Grimaldi, ver A. Bermejo de la Rica (1942); e D. Ramos Pérez (1974, p. 15-20).

19. Cf. D. Ramos Pérez (1974, p.23).

20. Cf. T. R. Smith (1966, p. 69). 
21. A tese do desconhecimento português do Mapa Geográfico de América Meridional de Juan de la Cruz Cano y Olmedilla parece ser reforçada pelo fato de, pouco antes da assinatura do Tratado de Santo Ildefonso, Luís Pinto de Sousa Coutinho, em suas Consideraçoens sobre o Tratado de Limites das Conquistas [entre 1776 Ago. 29 e 1777 Out.1], não fazer qualquer referência a esse mapa, ao passo que mostra conhecer o texto da Disertación Histórica y Geografica, de Jorge Juan e Antonio de Ulloa sobre o Meridiano de Demarcação. Ver J. C. Garcia e A. F. de Almeida $(2000$, p. $27-30 ; 17-18)$

22. Ver T. R. Smith (1966, p. 68-70).

23. Idem, ibidem. quanto se ignora o papel real que - à parte de sua utilização pela Junta Consultiva e pelos ministros da Coroa espanhola na preparação das negociações de paz com Portugal - o mapa desempenhou nas negociações do Tratado de Santo Ildefonso. Não se conhece qualquer referência a este mapa feita pelos negociadores portugueses, e é legítimo perguntar se, de fato, terão visto o mapa antes da assinatura do tratado. No entanto, se não foi este o mapa que serviu de base às negociações de novos limites para os domínios sul-americanos, seria interessante saber qual foi a cartografia de que se serviram os negociadores portugueses e espanhóis, uma vez que, ao contrário do que aconteceu no Tratado de Madri de 1750, neste tratado não se elaborou um mapa comum com o traçado da linha de fronteira acordada, como foi o caso do Mapa das Cortes $^{21}$.

Não está claro o que se passou nos finais do século XVIII, que levou os ministros e diplomatas espanhóis a procurar desacreditar a exatidão do mapa feito por Cruz Cano e evitar a sua difusão. Se, graças às sucessivas alterações que the foram sendo feitas, já não havia, desde a segunda edição do mapa, vestígios significativos da linha de fronteira entre os domínios portugueses e espanhóis, a verdade é que o governo espanhol proibiu a reimpressão de novos mapas e tentou desacreditar o mapa, até porque, apesar da política de sigilo e de distribuição restrita inicialmente seguida, havia alguns exemplares em circulação ${ }^{22}$.

De fato, Tomás Lopez, em seu conhecido discurso de 1797, explicou esta política do governo espanhol com o fato de, na altura das negociações de limites com Portugal, o mapa de Cruz Cano ter-se revelado prejudicial aos interesses espanhóis, principalmente devido aos erros que apresentava em relação às fronteiras. Contudo, como já foi dito, não só a utilização do mapa nas negociações com Portugal não está provada, como a linha de fronteira só consta da primeira impressão do mapa - o que Tomás Lopez parecia ignorar, como bem sublinhou Thomas R. Smith. Assim, parece bem mais plausível, segundo este mesmo autor, que a tentativa de desacreditar o mapa, depois de Santo Ildefonso, inscreva-se na mesma política de sigilo já anteriormente seguida e que visava apenas evitar a divulgação, junto das potências estrangeiras, dos conhecimentos geográficos patentes no Mapa Geográfico de América Meridional. E isso estaria em perfeita sintonia com o fato de o mapa não ter sido entregue aos negociadores portugueses do Tratado de Santo Ildefonso ${ }^{23}$.

O certo é que, contra a vontade do governo espanhol, fez-se a difusão do mapa. Em 1785, em Madrid, num leilão de uma importante biblioteca, Carmichael, diplomata americano, comprou um exemplar da terceira edição do mapa e remeteu-o a Thomas Jefferson - na data embaixador americano em Paris. Este, no ano seguinte, enviou-o a William Faden, que em 1799 o reimprimiu em Londres, conforme as instruções de Jefferson. Contudo, mesmo antes de o mapa chegar às mãos de Faden, o conde de Floridablanca, ministro de Estado, já estava a par do projeto de Jefferson e apressou-se a escrever ao embaixador espanhol em Londres para que tentasse desacreditar o mapa: 
El mapa de America Meridional que se gravó aqui y no se ha permitido vender, está lleno de errores y faltas de exactitud en los puntos mas principales, y por eso no se ha publicado. Digalo Ud., y propaguelo asi, pues estandose gravando ahi de nuevo el mismo mapa, segun expresa V.S. en el no 7 de 24 de octubre, no merece el credito que querran darle los interesados en venderlo y es justo que se sepa ${ }^{24}$.

Talvez as diligências do embaixador espanhol junto a Faden expliquem, em parte, a sua demora na gravação do mapa de Cruz Cano. O certo é que não foram suficientes para impedi-la. Em 1790, o embaixador espanhol em Londres informava à sua corte que

este famoso grabador Faden tiene muy alentado el Mapa de la America Meridional q. ${ }^{\text {e se }}$ hizo alg. ${ }^{\circ s}$ años ha de orden de nuestra Corte. Yo he praticado qu. ${ }^{10}$ ha cabido para disuadir a él y a quantos andan en ello pero sin fructos. El unico modo de inutilizar esta obra inglesa seria concluir brevem. te el nuestro con las enmiendas y adiciones q' deba tener, publicarlo y venderlo, pues no cabe guardar secretas estas cosas y mucho menos quando ya una vez se imprimió y se destribuyeron algunos ejemplares. De conocim. ${ }^{\text {th }}$ hai tres en Londres ${ }^{25}$.

Talvez não seja errado pensar que Luís Pinto de Sousa Coutinho, visconde de Balsemão, que foi ministro plenipotenciário e enviado extraordinário de Portugal à corte de Londres entre 1774 e 1783, e, novamente, entre 1783 e 1788, tenha conhecido por esta mesma altura a terceira edição do mapa de Cruz $\mathrm{Cano}^{26}$. Não temos dados que nos permitam apoiar tal tese, mas ela não deixa de ser plausível. De acordo com o embaixador espanhol, havia, em 1790, pelo menos três exemplares do mapa em Londres e talvez o mesmo já acontecesse alguns anos antes. Além do mais, é praticamente impossível que o visconde de Balsemão, que se encontrava em Londres entre 1785 e 1788, não estivesse ao corrente do projeto, de Thomas Jefferson, de mandar reimprimir o mapa, principalmente devido às excelentes relações que mantinha com William Faden. Pensamos, assim, ser provável que a obtenção do mapa de Cruz Cano por parte dos diplomatas portugueses deva datar das duas últimas décadas do século XVIII.

governo espanhol não seguiu as sugestões do seu embaixador em Londres porque, em 1789, já fora decidido o envio das chapas de cobre para a recém-criada Real Calcografia, onde ficaram depositadas, juntamente com 151 exemplares do mapa, com ordem verbal do Ministro de Estado para que se não vendesse nenhum exemplar, por parecer não estar exato na demarcação dos limites dos domínios americanos com Portugal27. Foi só em 1802 que o mapa de Juan de la Cruz foi definitivamente reabilitado. Por ordem de D. Pedro de Cevallos, ministro de Estado de Carlos IV, foi solicitado a Francisco Requeña um parecer sobre o mapa. A experiência de Requeña enquanto cartógrafo dos territórios sul-americanos e como demarcador da fronteira com o Brasil no período posterior a Santo Ildefonso, principalmente na região amazônica, tornavam-no numa escolha natural para se pronunciar sobre o mapa de Cruz Cano. $O$ parecer de Requeña foi categórico acerca da qualidade do mapa e da impossibilidade de este ser utilizado contra os interesses espanhóis na América do Sul, uma vez que a única linha assinalada era a do meridiano de Tordesilhas, ficando patentes as usurpações territoriais dos portugueses a ocidente desta linha ${ }^{28}$. A consequência
24. CARTA do Marquês de Floridablanca ao Marquês del Campo, Madrid, 22 de Dezembro de 1786, apud A. Barreto (1973, p. 282).

25. Ver ibidem, quando cita a Carta do embaixador espanhol em Londres, de 5 de Outubro de 1790 .

26. Para o período de permanência em Londres de Luís Pinto de Sousa Coutinho recorremos à obra de L. T. de Sampayo (1983, p. 228).

27. Ver R. Donoso (1963, p.162); e também T. R. Smith (1966, p. 70-71).

28. Ver R. Donoso (1963, p.163-167). 
29. Ver T. R. Smith (1966, p.71-72) do parecer de Requeña foi o levantamento das restrições à circulação do mapa de Cruz Cano, que foi distribuído por vários ministérios e posto à venda pela Real Calcografia ${ }^{29}$.

\section{REFERÊNCIAS}

ADONIAS, I. Mapas e planos manuscritos relativos ao Brasil Colonial: 1500-1822. Brasília: Ministério das Relações Exteriores, 1960.

ALDEN, D. Royal government in colonial Brazil. Berkeley and Los Angeles: University of California Press, 1968.

BARRETO, A. Bibliografia Sul-riograndense: a contribuição portuguesa e estrangeira para o conhecimento e a integração do Rio Grande do Sul. Rio de Janeiro: Conselho Federal de Cultura, 1973-1976, 2v.

BERMEJO DE LA RICA, A. Antecedentes diplomáticos de la campaña de Don Pedro de Cevallos en el Uruguay en 1777. Revista de Indias, Madrid, vol.III, nº 8, p. 323-371, 1942.

DONOSO, R. El Mapa de la América Meridional de La Cruz Cano y Olmedilla. Revista Chileña de Historia y Geografia, Santiago, nº131, p. 121-175, 1963.

GARCIA, J. C.; ALMEIDA, A. F. de. A América portuguesa nos manuscritos da Biblioteca Pública Municipal do Porto. In: A TERRA de Vera Cruz, Viagens, descrições e mapas do séc. XVIII. Porto: Biblioteca Pública Municipal do Porto, 2000, p. 9-62.

GUILLÉN Y TATO, J. F. Monumenta cartographica indiana, vol.I (Regiones del Plata y Magallanica). Madrid: Ministerio de Asuntos Exteriores, 1942.

NÚÑEZ DE LAS CUEVAS, R. Historia de la cartografia española. In: CICLE DE CONFERÈNCIES SOBRE HISTÒRIA DE LA CARTOGRAFIA, La Cartografia de la Península Ibèrica i la seva extensió al Continent Americà, Barcelona: Generalitat de Catalunya/ Department de Politica Territorial i Obres Públiques/ Institut Cartogràfic de Catalunya, 1991, p.155-223.

RAMOS GOMEZ, L. Jorge Juan y Antonio de Ulloa y el Meridiano de Tordesillas: La Disertacion Historica y Geografica (1747-1776). In: AA.VV. El Tratado de Tordesillas y su época, tomo III,. Madrid: Sociedad V Centenario del Tratado de Tordesillas/ Comissão Nacional para as Comemorações dos Descobrimentos Portugueses, 1995, p.1561-1592.

RAMOS PÉREZ, D. Los criterios contrarios al Tratado de Tordesillas en el Siglo XVIII. Determinantes de la necesidad de su anulación. Revista da Universidade de Coimbra, Coimbra, vol. 25, 1974 [separata].

RAMOS PÉREZ, D. Historia secreta de unos mapas de Petroschi y Bellin, en relacion con las conversaciones sobre limites del Brasil previstas para 1776, Anais Hidrográficos, Rio de Janeiro, T.XXXIII (Suplemento). p. 21-62,1976.

SAMPAYO, L. T. de. Estudos históricos. Lisboa: Ministério dos Negócios Estrangeiros, 1983. 
SANZ TAPIA, A. La delimitación definitiva de Tordesillas: el Tratado de San Ildefonso (1777). In: AA.VV., El Tratado de Tordesillas y su época, tomo III. Madrid: Sociedad V Centenario del Tratado de Tordesillas/ Comissão Nacional para as Comemorações dos Descobrimentos Portugueses, 1995, p. 1653-1686.

SMITH, T. R. Cruz Cano's map of South America, Madrid, 1775: its creation, adversities and rehabilitation. Imago Mundi, London, vol. 20, p. 49-78 1966.

VV.AA. Tesoros de la cartografia española: exposicion con motivo del XIX Congreso Internacional de Historia de la Cartografia, Madrid, 2001. Catalogo. Madrid: Biblioteca Nacional; Caja Duero, 2001. 